\title{
JNK Plays a Key Role in Tau Hyperphosphorylation in Alzheimer's Disease Models
}

\author{
Cristina Ploia ${ }^{\mathrm{a}, 1}$, Xanthi Antoniou ${ }^{\mathrm{a}, 1}$, Alessandra Sclip ${ }^{\mathrm{a}}$, Valentina Grande ${ }^{\mathrm{a}, \mathrm{d}}$, Daniele Cardinetti ${ }^{\mathrm{a}}$, \\ Alessio Colombo ${ }^{\mathrm{a}, 2}$, Nadia Canu ${ }^{\mathrm{b},}$, Luisa Benussi ${ }^{\mathrm{c}}$, Roberta Ghidoni ${ }^{\mathrm{c}}$, Gianluigi Forloni ${ }^{\mathrm{a}}$ and \\ Tiziana Borsello ${ }^{\mathrm{a}, *}$ \\ ${ }^{\mathrm{a}}$ Istituto di Ricerche Farmacologiche "Mario Negri", Milano, Italy \\ ${ }^{\mathrm{b}}$ Dipartimento di Neuroscienze, Università di Tor Vergata, Rome, Italy and Istituto di Neurobiologia \\ e Medicina Molecolare, CNR, Rome, Italy \\ ${ }^{\mathrm{c}}$ Proteomics Unit NeuroBioGen Lab-Memory Clinic, IRCCS Centro S. Giovanni di Dio-Fatebenefratelli, \\ Brescia, Italy \\ ${ }^{\mathrm{d}}$ NICO, Scientific Institute of the Cavalieri-Ottolenghi Foundation Neuroscience Institute of Turin, \\ Orbassano (To), Italy
}

Accepted 9 April 2011

\section{INTRODUCTION}

c-Jun $\mathrm{N}$ terminal kinases (JNKs) belong to the family of serine and threonine mitogen-activated protein

\footnotetext{
1 These two authors contributed equally to this work.

2 Present Address: DZNE - German Center for Neurodegenerative Diseases, Schillerstrasse 44, 80336 Munich, Germany.

*Correspondence to: Tiziana Borsello, Neuronal death and Neuroprotection Unit, Neuroscience Department, Istituto di Ricerche Farmacologiche "Mario Negri", Via La Masa 19, 20156 Milano, Italy. Tel.: +39 02 39014469/39014592; Fax: +39 02 3546277; E-mail: tiziana.borsello@marionegri.it.
}

kinases (MAPKs) and are involved in numerous cellular processes, such as proliferation, differentiation, development, inflammation, and apoptosis [1]. In the central nervous system (CNS) the JNK signaling pathway is important in controlling brain functions under both normal and pathological conditions [2].

In particular, in Alzheimer's disease (AD), activation of JNK [3-6] as well as p-c-jun [7, 8], correlate with disease progression. Furthermore, JNK is activated by amyloid- $\beta(\mathrm{A} \beta)$ fragments $[9,10]$ and causes phosphorylation of both amyloid- $\beta$ protein precursor 
(A $\beta P P), \beta-C$-terminal fragment ( $\beta-C T F)$ [11-14], and tau $[4,15-18]$.

The amyloid-cascade hypothesis of AD considers the production of $\mathrm{A} \beta$ a key event in $\mathrm{AD}$ pathology [19], however another school of thought sustains that the neurofibrillary tangles of hyperphosphorylated tau, as opposed to amyloid deposits, are more influential to dementia associated with $\mathrm{AD}$ [20]. In line with the above, the decrease of tau phosphorylation has been correlated to improvement of memory and to reduction of neurodegeneration in transgenic mice over-expressing mutant human tau (P301 L) [21] and in double transgenic mice co-expressing human mutant $\mathrm{A} \beta \mathrm{PP}$ and tau [22]. Thus hyperphosphorylated tau may be a primary cause of the disorder and therefore understanding its regulation is important for the development of therapeutic strategies.

Tau can be phosphorylated at multiple sites by an array of kinases, and the phosphorylation events that lead to AD have been extensively studied [23-25]. In particular JNK is known to phosphorylate tau at S202/T205 and S422 [26, 27]. These two phosphorylation sites are strictly associated with $\mathrm{AD}$ pathogenesis. Luna-Munoz and colleagues [25] reported that in AD brains, phosphorylation at the S202/T205 residues of tau, recognized by the AT8 antibody, occurs at an early stage of the disease, while phosphorylation at $\mathbf{S} 422$ precedes and correlates with tangle formation [28].

To study the involvement of the JNK pathway on tau hyperphosphorylation we analyzed the action of JNK at S202/T205, S422 using three different models: differentiated cortical neurons, as an in vitro control model; transgenic AD mice (TgCRND8), to assess the contribution of JNK in tau phosphorylation in an vivo model; and finally human AD fibroblasts, which are easily accessible from patients and are a good model to validate potential therapeutic strategies. The latter also offer an excellent way to study the mechanisms involved in the development of AD [29].

To achieve specific inhibition of JNK in vitro and in vivo, we used a cell permeable JNK inhibitor peptide (D-JNKI-1), which prevents JNK action without interfering with its activation/phosphorylation [30,31] in low concentrations $(2 \mu \mathrm{M})$ and modulates the enzymatic activity in high concentrations ( 4 and $6 \mu \mathrm{M})$, as we have previously demonstrated [32]. We analyzed the effect of D-JNKI-1 in these models and we proved that JNK plays a key role in tau hyperphosphorylation on S202/T205 and S422. A better understanding of the JNK pathway activation/inhibition is of great therapeutic interest and may have important implications for the fight against $\mathrm{AD}$.

\section{MATERIALS AND METHODS}

\section{Cortical neuronal cultures}

Primary neuronal cultures were obtained from the cerebral cortex of two days postnatal rats, incubated with 200 U of papain (P3125, Sigma Aldrich, St Louis, USA) $\left(30^{\prime}-34^{\circ} \mathrm{C}\right)$, then with trypsin inhibitor (T9253, Sigma Aldrich) $\left(45^{\prime}-34^{\circ} \mathrm{C}\right)$, and subsequently mechanically dissociated. Neurons were plated in $35 \mathrm{~mm}$ dishes $\left(\sim 7 \times 10^{5}\right.$ cells $/$ dish $)$ pre-coated with $25 \mu \mathrm{g} / \mathrm{ml}$ poly-D-lysine (P6407, Sigma Aldrich). Plating medium was B27/neurobasal-A (17504044, 10888, Gibco-Invitrogen, Paisley, Scotland, UK) supplemented with $0.5 \mathrm{mM}$ glutamine (25030, Gibco-Invitrogen), $100 \mathrm{U} / \mathrm{ml}$ penicillin, and $100 \mu \mathrm{g} / \mathrm{ml}$ streptomycin (15140-122, Gibco-Invitrogen). To avoid proliferation of glial cells and in order to achieve 95\% purity in neuronal cultures, $\mathrm{AraC}(10 \mu \mathrm{M}),(\mathrm{C} 6645$, Sigma Aldrich) was added to the media at 2 days from plating date (2DIV).

The experiments were performed 12 days from plating date (12DIV), at which time neurons are considered differentiated [33-35]. All experiments were repeated using at least six independent culture preparations.

Neurons were treated with D-JNKI-1 (2-4-6 $\mu \mathrm{M})$ (Istituto di Ricerche Farmacologiche "Mario Negri", Milano, Italy) for $24 \mathrm{~h}$. This D-retro-inverso inhibitor of JNK is composed exclusively of D- instead of Lamino acids and is synthesized in a reverse order to preserve functionality. The inactive peptide D-TAT was used as a control to prove the specificity of D-JNKI1, as previously shown by Borsello et al. [30]. All experimental procedures on animals were performed in accordance with the European Communities Council Directive of 24 November 1986 (86/609/EEC) and all efforts were made to minimize animal suffering.

\section{Subjects and human fibroblasts cultures}

Patients included in this study were recruited and evaluated at the Memory Clinic of IRCCS "Centro San Giovanni di Dio-Fatebenefratelli", Brescia, Italy. Written informed consent was obtained from all subjects or, where appropriate, their caregivers, following the procedures approved by the hospital local ethical committee. Fibroblast primary cultures were derived from the dermal biopsy of $\mathrm{AD}$ and control subjects (NA) as previously described [36]. Global cognition was investigated by Mini-Mental State Examination (MMSE). Demographic features of fibroblasts donors: AD patients, $n=7$, mean age $=72.2 \pm 6.94$ years, 
gender $=80 \%$ female, $\mathrm{MMSE}=17.4 \pm 5.9$; NA controls subjects, $n=6$, mean age $=62.6 \pm 4.28$ years, gender $=60 \%$ female, MMSE $=28.8 \pm 1.1$. Fibroblasts from unrelated healthy controls (NA) were obtained from Fatebenefratelli Biological Repository (F-BR) of IRCCS "Centro San Giovanni di DioFatebenefratelli", Brescia, Italy. Cells were cultured at $37^{\circ} \mathrm{C}$ in $5 \% \mathrm{CO}_{2} / 95 \%$ air in Eagle's Minimum Essential Medium (31095, Gibco-Invitrogen), 10\% FBS (SH30070.03, Hyclone-Thermo Scientific, Rockford, USA), 100 U/ml P/S (15140-122, GibcoInvitrogen), $1 \% \mathrm{v} / \mathrm{v}$ Non Essential Amminoacids (M7145, Sigma Aldrich), 2 mM L-Glutamine (25030, Gibco-Invitrogen). The different fibroblast cell cultures were plated and analyzed at the same passage number. Fibroblasts were plated in $35 \mathrm{~mm}$ dishes, $\mu$ Dishes (80826, Ibidi, Martinsried, Germany) or 96 well plate. $70-80 \%$ confluent cultures were treated with D-JNKI-1 (10-150 $\mu \mathrm{M})$ (Istituto di Ricerche Farmacologiche "Mario Negri”, Milano, Italy) for $24 \mathrm{~h}$.

\section{Cell peptide uptake}

$2 \mu \mathrm{M}$ of FITC-labeled D-JNKI-1 (Istituto di Ricerche Farmacologiche "Mario Negri") was added to the culture medium of cortical neurons for $24 \mathrm{~h}$ at $37^{\circ} \mathrm{C}$. $50 \mu \mathrm{M}$ of FITC-labeled D-JNKI-1 was added to the culture medium of fibroblasts (70-80\% confluent) for $24 \mathrm{~h}$ at $37^{\circ} \mathrm{C}$. Cells were rinsed three times in PBS and fed with fresh medium. Free FITC was used as a control for background signals. Peptide internalization was monitored by fluorescence in live cells using a confocal laser scanning microscope. Excitation was performed at $488 \mathrm{~nm}$.

\section{Real-time reverse transcription- $P C R$}

Total RNA was isolated from cortical neurons using RNeasy Mini kit (Qiagen GmbH, D-40724 Hilden) and then treated with DNase (Dnase I, Amplification Grade, Invitrogen, Carlsbad, CA 92008 USA). Extracted RNA was quantified using Agilent RNA 6000 Nano Kit and Agilent Bioanalyzer 2100 (Agilent Technologies, Hewlett, Packard - Str.8, 76337 Walbronn, Germany). Primer and probe sequences were designed using Beacon Designer 3.0 software (Premier Biosoft International, Palo Alto, CA) according to specification for SYBR-green [37]. Sequences for the forward primer and reverse primer for tau and for $\beta$-actin from Zhao et al. 2007 [38]. $\beta$-actin mRNA expression, which is not modulated by the peptide as previously demonstrated [13], was used as an endoge- nous control. Real-time PCR reaction was performed in a final volume of $25 \mu \mathrm{l}$ containing $45 \mathrm{ng}$ of cDNA, $200 \mathrm{nM}$ of both primers, $12.5 \mu \mathrm{l}$ of SYBR-green PCR Master Mix containing: SYBR-green I dye, AmpliTaq Gold DNA Polymerase, dNTPs, Passive Reference Rox $^{\mathrm{TM}}$ dye, using Applied Biosystems 7300 RealTime PCR System (Applied Biosystems, Warrington, $\mathrm{UK})$. The amplification protocol included $2 \mathrm{~min}$ at $50^{\circ} \mathrm{C}, 10 \mathrm{~min}$ at $95^{\circ} \mathrm{C}$, followed by 60 cycles of $15 \mathrm{~s}$ at $95^{\circ} \mathrm{C}$ for denaturation and $30 \mathrm{~s}$ at $60^{\circ} \mathrm{C}$ for annealing and extension. The relative expression of tau was calculated by comparative method (Comparative $\mathrm{C}_{\mathrm{T}}$ method - User Bulletin \#2, Applied Biosystems).

\section{TgCRND8 mice}

Transgenic hemizygous TgCRND8 mice carry a

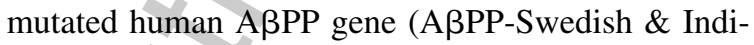
ana mutations on $129 \mathrm{SV}$ strain) and show age-related amyloid plaque accumulation at around 4/5 months of age and tangles formation at the age of 7 months [39].

A post-symptomatic treatment with D-JNKI-1 (IP injection- $22 \mathrm{mg} / \mathrm{kg}$ ) was performed on TgCRND8 mice for 4 months (every 21 days), starting at the age of 4 months. Mice were sacrificed 3 weeks after the last injection. In these conditions the treatment has no side effects. Mice were divided in 4 groups: wild type treated with vehicle, wild type treated with D-JNKI-1, transgenic animals treated with vehicle and transgenic mice treated with D-JNKI-1. At least seven animals were analyzed for each group.

\section{Immunofluorescence analysis}

Cortical neurons and fibroblasts were plated on $\mu$-Dishes (80826, Ibidi, Martinsried, Germany) and fixed in $4 \%$ paraformaldehyde, $5 \%$ sucrose-PBS for 30 min on ice. Nonspecific antibody binding sites were blocked for $1 \mathrm{~h}$ with $10 \%$ normal goat serum in PBS and triton $0.3 \%$ at room temperature. Primary antibodies specific for PHF-tau clone AT8 (MN1020, Thermo Scientific, Rockford, USA) $(1: 100)$ was diluted in PBS-Triton $0.1 \%$, NGS $1 \%$ and used overnight at $4{ }^{\circ} \mathrm{C}$. Cortical neurons were rinsed in PBS and exposed to the secondary Alexa 546 antibody (A11030, Invitrogen, Molecular Probes, Eugene, Oregon, USA) for $1 \mathrm{~h}$ at room temperature. For fibroblasts TSA Fluorescence Systems was used for signal amplification (Cyanine 5 System, NEL705A001 KT, PerkinElmer, Boston, MA). Hoechst reagent (33258, Invitrogen) $(1: 500)$ in PBS was used to stain the nuclei. Staining for F-actin cytoskeleton was performed with 
Rhodamine-Phalloidin (R415, Invitrogen, Molecular Probes) (1:40 in PBS) for $30 \mathrm{~min}$ at room temperature.

\section{Cytotoxicity Assay}

Toxicity following D-JNKI-1 treatment was evaluated by a Lactate dehydrogenase (LDH) assay. LDH released in the medium was measured using the Cytotox 96 non radioactive cytotoxicity assay kit (G1780, Promega, WI, USA). All cytotoxicity assays were performed in triplicates.

\section{Cellular lysis}

Total protein extracts were obtained by washing cells twice in ice-cold PBS and lysed $\left(20^{\prime}-4^{\circ} \mathrm{C}\right)$ in $1 \%$ Triton $\mathrm{x}-100$ lysis buffer supplemented with proteases (11873580001, Roche) and phosphatases (PhosStop 04906845001, Roche) inhibitors [31].

\section{Western blot analysis}

Protein concentrations were quantified using Bradford Assay (Bio-Rad Protein Assay 500-0006, Munchen, Germany) and $20 \mu \mathrm{g}$ of whole cell proteins or brain homogenates were separated by $8-10 \%$ SDS polyacrylamide gel. PVDF membranes were blocked in Tris-buffered saline (5\% no fat milk powder, $0.1 \%$ Tween 20$)$ ( $1 \mathrm{~h}$, room temperature). Primary antibodies were diluted in the same buffer (incubation overnight, $4^{\circ} \mathrm{C}$ ) using: anti PHF-tau clone AT8 (MN1020, Thermo Scientific, Rockford, USA), $p$ tau pSer422 (T 7944, Sigma), anti-tau clone tau-5 (MAB361, Millipore, Billerica, Ma), p-c-Jun Ser73 (9164, Cell Signaling, Danvers, MA), c-Jun (9165, Cell Signaling), P-JNK (G-7) (sc-6254, Santa Cruz Biotechnology, Santa Cruz, California), JNK (9252, Cell Signaling). All blots were normalized to Actin (MAB1501, Chemicon-Millipore, Billerica, Ma) and at least three independent experiments were performed. Western blots were quantified by densitometry using Quantity One software (Biorad).

\section{Statistical analysis}

Quantitative data were analyzed by paired Student's $t$-test with two-tailed distribution or One Way-, Two Way- ANOVA (Tukey's post hoc test). A $p$ value of $<0.05$ was considered significant.

\section{RESULTS}

D-JNKI-1 treatment prevents $c$-Jun and tau phosphorylation in rat cortical neurons without initiating cell death processes

The efficacy of D-JNKI-1 was tested by assessing the uptake of FITC-labeled D-JNKI-1 in adult cortical neurons in control conditions. Briefly, cells were exposed to $2 \mu \mathrm{M}$ of FITC-labeled D-JNKI-1 for $24 \mathrm{~h}$ at $37^{\circ} \mathrm{C}$. As shown in Fig. 1A, FITC- D-JNKI-1 penetrated neurons and accumulated into the cell bodies. In order to ascertain that the concentrations used were not toxic we measured LDH leakage in the neuronal media, an established index of neuronal death. Treatment with 2, 4, and $6 \mu \mathrm{M}$ D-JNKI-1 for $24 \mathrm{~h}$ did not induce toxicity (Fig. 1B) as previously demonstrated [13].

The basal activity of JNK signaling pathway is high in neurons. The efficiency of D-JNKI-1 to prevent phosphorylation of c-Jun, a known JBD dependent target of JNK, was assessed by Western blotting. As expected, treatment with D-JNKI-1 led to inhibition of c-Jun phosphorylation compared to control conditions (Fig. 1C), [13, 30, 32, 40]. Densitometry quantification confirmed a $28 \%, 90 \%$ and $95 \%$ decrease of c-Jun phosphorylation following treatment with increasing concentrations of D-JNKI-1 (2-4-6 $\mu \mathrm{M}$ respectively, Fig. 1C,D), $(p<0.01$ and $p<0.001$, One Way ANOVATukey's post-hoc Test) ( \pm S.E.M.). We subsequently analyzed the effect of D-JNKI-1 on activation of JNK. As already demonstrated by Repici et al., [32] at 4 and $6 \mu \mathrm{M}$, D-JNKI-1 interferes with the two upstream activators, MKK7 and MKK4, inducing a reduction of the $\mathrm{p}-\mathrm{JNK} / \mathrm{JNK}$ ratio. We could indeed show that DJNKI-1 reduced the p-JNK/JNK ratio by 63 and $74 \%$ at 4 and $6 \mu \mathrm{M}$ respectively (Fig. 1C-E) $(p<0.01$, One way ANOVA- Tukey's Test) ( \pm S.E.M.). The control TAT-peptide did not prevent JNK activity as previously demonstrated (data not shown) [30, 31].

We then analyzed the effect of D-JNKI-1 on tau phosphorylation. $p$-tau and total tau levels were determined by Western blotting (Fig. 2). Treatment with 4 and $6 \mu \mathrm{M}$ D-JNKI-1 for $24 \mathrm{~h}$ reduced $p$-tau (clone AT8)/tau (clone tau-5) ratio by $40 \%$ and $75 \%$ respectively $(p<0.05$ and $p<0.01$, One way ANOVATukey's post-hoc test), ( \pm S.E.M.), (Fig. 2A-B), while the $p$-tau (clone AT8)/Actin ratio decreased by $70 \%$ and $90 \%$ respectively $(p<0.01$, One way ANOVATukey's post-hoc test) ( \pm S.E.M.), (Fig. 2A-C). Similarly, treatment with 4 and $6 \mu \mathrm{M}$ D-JNKI-1 reduced $p$-tau S422/tau (clone tau-5) ratio by $54 \%$ and $51 \%$ 
A

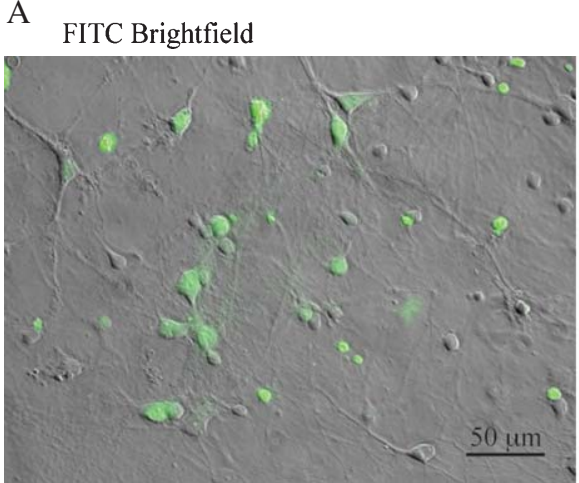

FITC

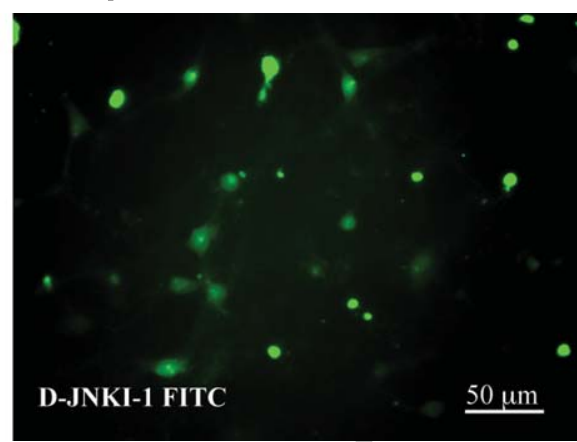

LDH D-JNKI-1 24h

B

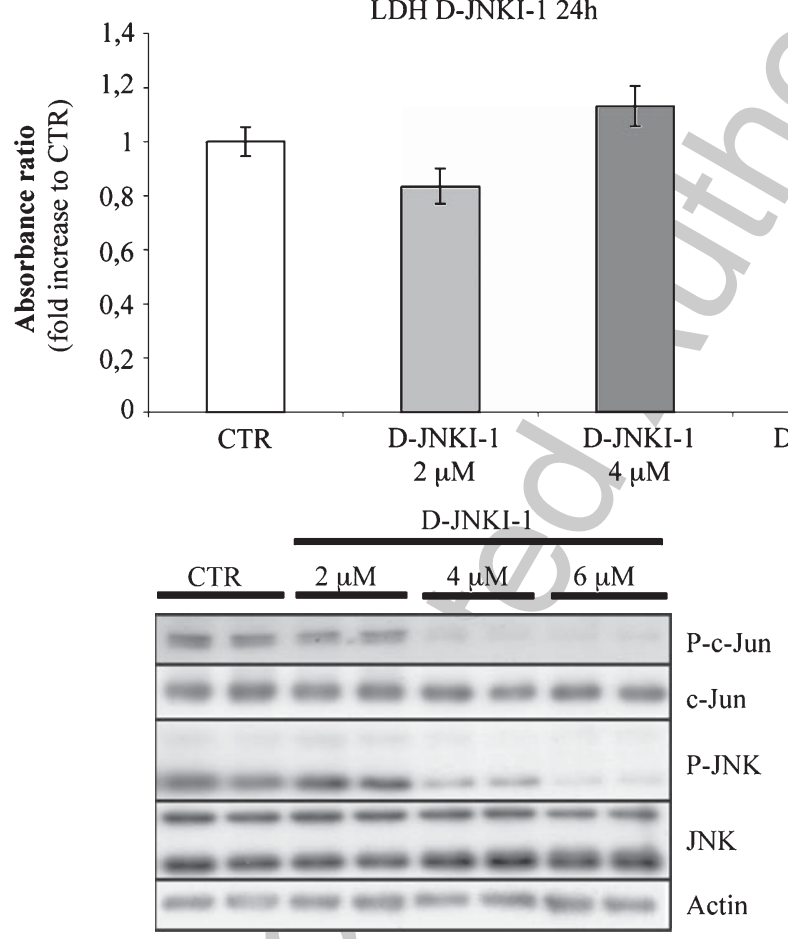

$\mathrm{D}$

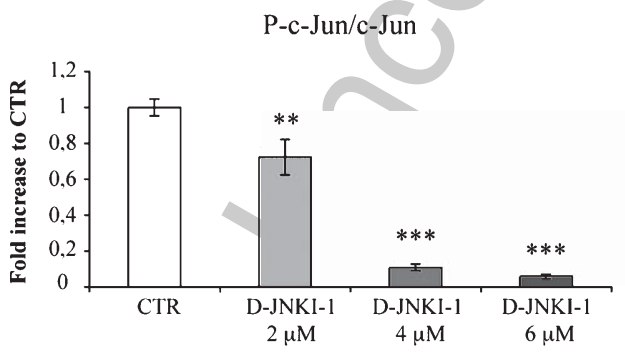

E

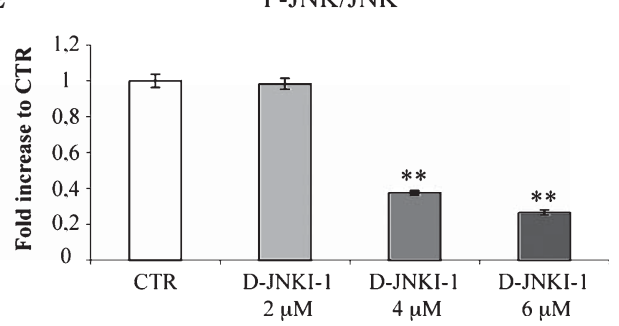

Fig. 1. D-JNKI-1 penetrates neurons successfully, it is not toxic and inhibits c-Jun and JNK phosphorylation in a concentration dependent manner. A) Exposure of neurons to $2 \mu \mathrm{M}$ FITC-labeled D-JNKI-1 for $24 \mathrm{~h}$ leads to accumulation of the peptide within the cell bodies (left panel: Bright Field images with FITC-D-JNKI-1, right panel FITC-D-JNKI-1 only, scale bar $50 \mu \mathrm{m})$. B) Incubation with D-JNKI-1 (2-4-6 $\mu$ M for $24 \mathrm{~h}$ ) is not toxic to neurons as indicated by the absence of LDH leakage ( $p>0.05$, One Way ANOVA). C) Representative Western blots showing reduction of p-c-Jun and p-JNK in rat cortical neurons treated with D-JNKI-1 2-4-6 $\mu$ M for 24 h. D) Densitometric quantification of p-c-Jun/c-Jun ratio revealed a $28 \%, 90 \%$ and $95 \%$ decrease after treatment with increasing concentrations of D-JNKI-1 (2-4-6 $\mu$ M), and E) a reduction of p-JNK/JNK ratio by $63 \%$ and $74 \%$ at 4 and $6 \mu \mathrm{M}$. Loading control: Actin. (One Way ANOVA - Tukey's Test $-{ }^{*} p<0.05$, $* * p<0.01)( \pm$ S.E.M.). 
A
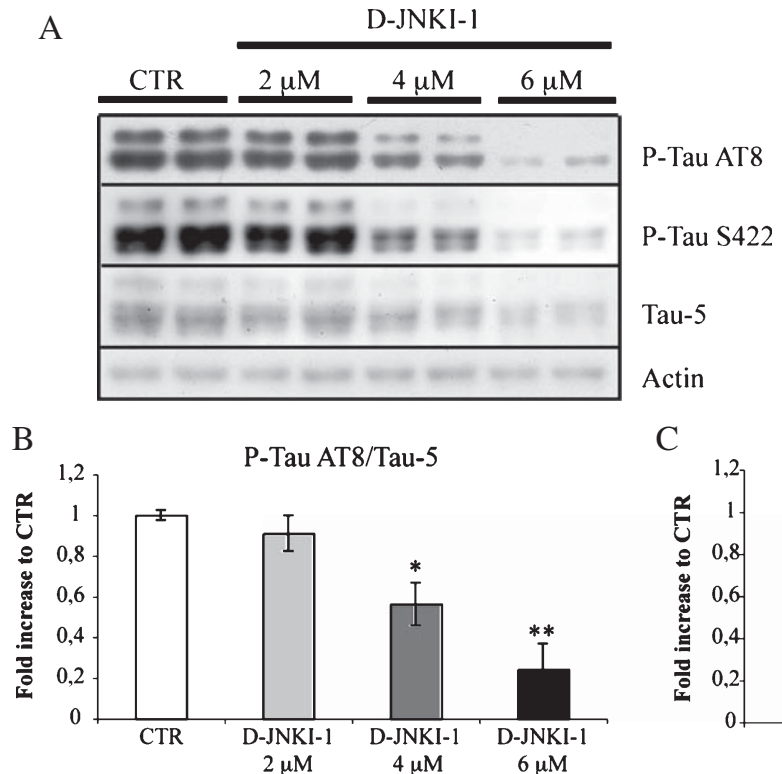

$\mathrm{C}$

$\mathrm{D}$
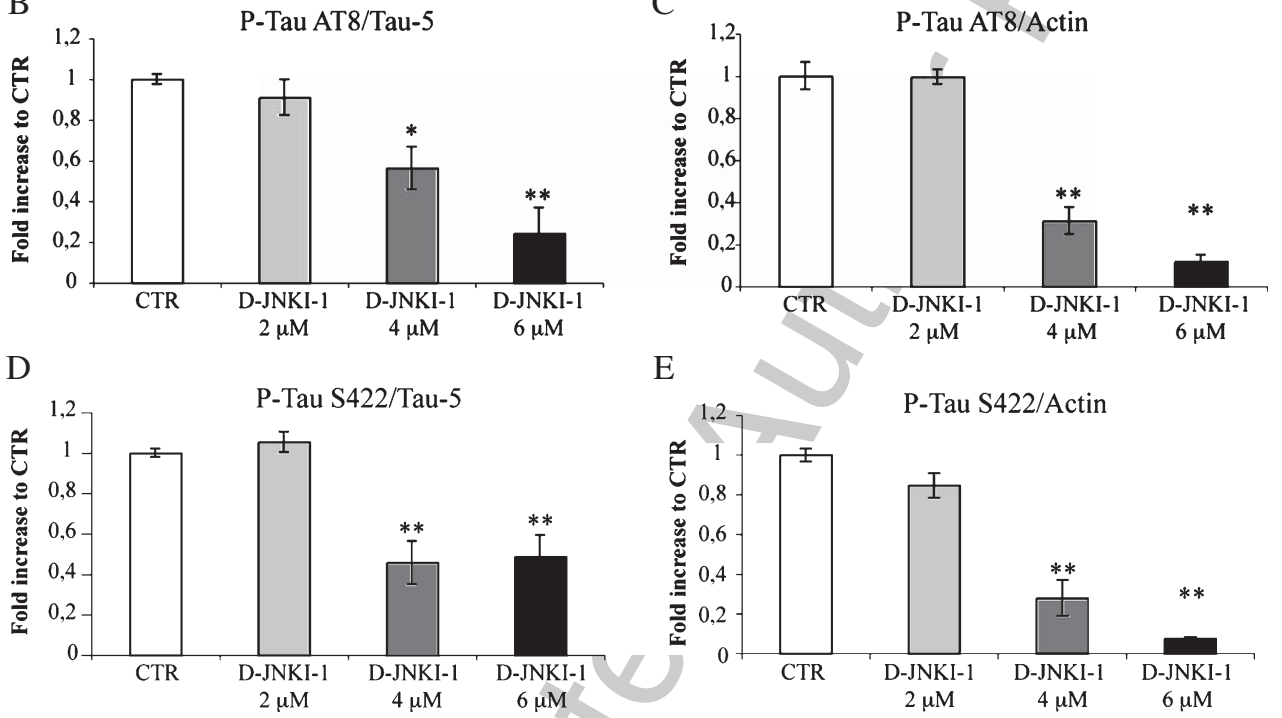

$\mathrm{E}$
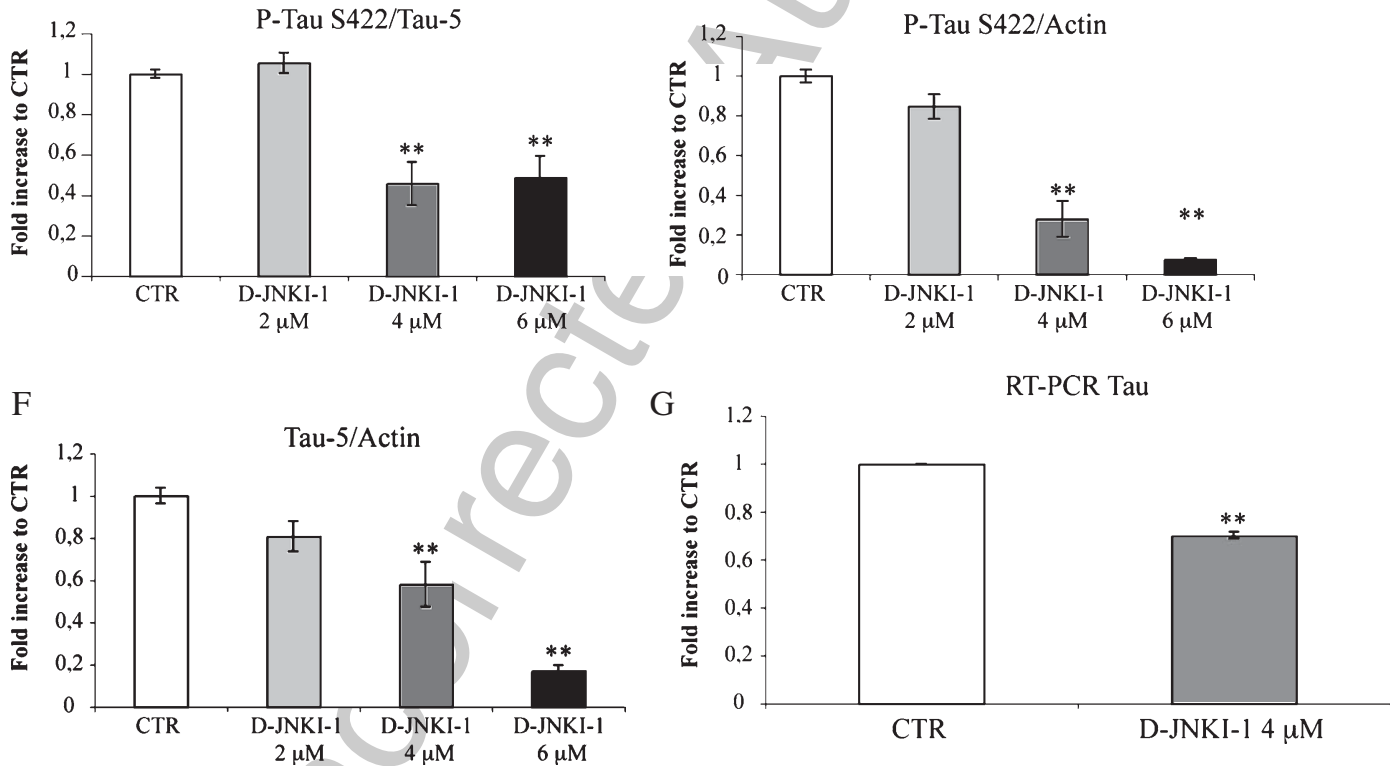

Fig. 2. JNK inhibition reduces tau phosphorylation in cortical neuronal cultures. A) Representative Western blots showing reduction of $p$-tau AT8, $p$-tau S422, and tau protein levels following treatment of neurons with increasing concentrations of D-JNKI-1 for $24 \mathrm{~h}$. B) Densitometric quantification of $p$-tau AT8/Tau-5 ratio revealed a decrease (40-75\%) after treatment with D-JNKI-1 (4-6 $\mu \mathrm{M})$ and C) densitometric quantification of $p$-tau AT8/Actin ratio revealed a 70-90\% decrease after treatment with D-JNKI-1 (4-6 $\mu \mathrm{M})$. D) D-JNKI-1 (4-6 $\mu \mathrm{M})$ reduces $p$-tau S422/Tau-5 ratio by $54-51 \%$ respectively and E) D-JNKI-1 $(4-6 \mu \mathrm{M})$ reduces $p$-tau S422/Actin ratio by $72-93 \%$. F) D-JNKI-1 treatment $(4-6 \mu \mathrm{M})$ reduces total levels of tau as revealed by the reduction of the Tau-5/Actin ratio (40-80\%). Loading control: Actin. (One Way ANOVA - Tukey's Test $\left.{ }^{*} p<0.05,{ }^{* *} p<0.01\right)( \pm$ S.E.M.). G) Real Time PCR revealed that tau mRNA levels are decreased by $30 \%$ after treatment with $4 \mu$ M D-JNKI-1 (Student's $t$-test $-* p<0.01)( \pm$ S.E.M.).

respectively $(p<0.01$, One way ANOVA- Tukey's Test) ( \pm S.E.M.), (Fig. 2A-D). The $p$-tau S422/Actin ratio was also decreased by $72 \%$ and $93 \%$ following treatment with increasing concentrations of D-JNKI$1(p<0.01$, One way ANOVA- Tukey's post-hoc test) ( \pm S.E.M.), (Fig. 2A-E).
Interestingly, D-JNKI-1 treatment led to an overall reduction of tau protein levels, as shown by the decrease of tau (clone tau-5)/Actin ratio by $40 \%$ and $80 \%(4 \mu \mathrm{M}$ and $6 \mu \mathrm{M}$ D-JNKI-1) $(p<0.01$, One Way ANOVA- Tukey's post-hoc test) ( \pm S.E.M.), (Fig. 2A-F). The effect of D-JNKI-1 on tau was fur- 
TgCRND8 mice are characterized by numerous $\mathrm{A} \beta$ deposits (3-5 months of age) in the hippocampus,

A

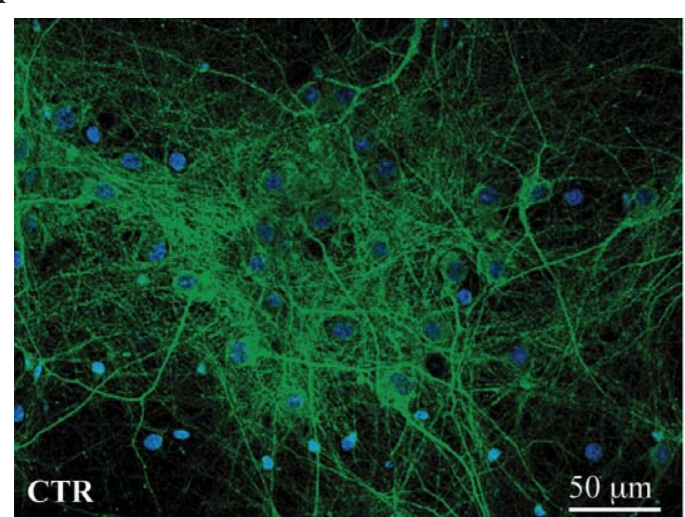

B

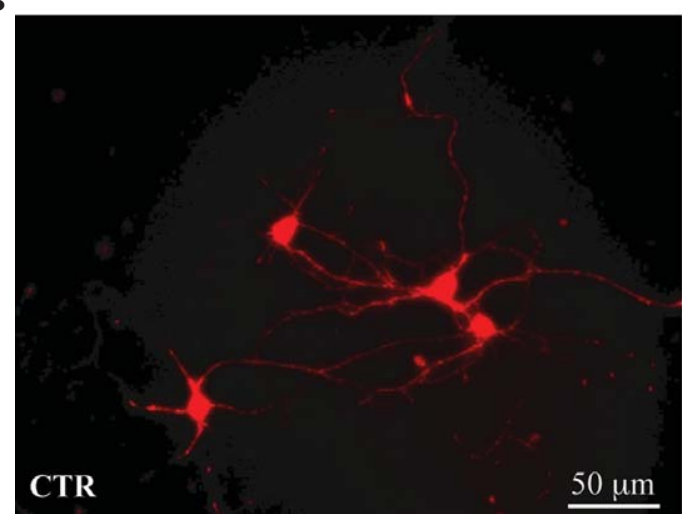

cortex and other brain areas, as well as hyperphosphorylated tau (7-12 months of age) and impairment in learning and memory functions $[16,39,41]$. Moreover, in the neocortex and hippocampus of this transgenic mouse model ( 7 and 12 months of age) activity of JNK is increased in respect to $\mathrm{Wt}$ controls, and $p$-JNK is localized within amyloid plaques [16].

Herein we investigated if a chronic treatment (4 months) with D-JNKI-1 (22 mg/kg) prevents tau phosphorylation in TgCRND8 mice. Previous reports have extensively demonstrated that in adult mice the peptide is able to cross the blood-brain barrier, penetrate the cerebral cortex within $1 \mathrm{~h}$ and $30 \mathrm{~min}$ after an intraperitoneal injection $[30-32,40]$, and remain stable in the brain parenchyma for 3 weeks. Consequently, D-JNKI1 was injected in TgCRND8 mice and wt 129 sv mice every 21 days intraperitoneally, starting from 4 to reach 8 months of age.

C-Jun was activated in TG-CTR mice compared to WT-CTR mice both in the cortex (Fig. 4A,B) and hippocampus (Fig. 4E,F) demonstrating a role of JNK pathway in $\mathrm{AD}$ pathology $(p<0.05$, two-way ANOVA,
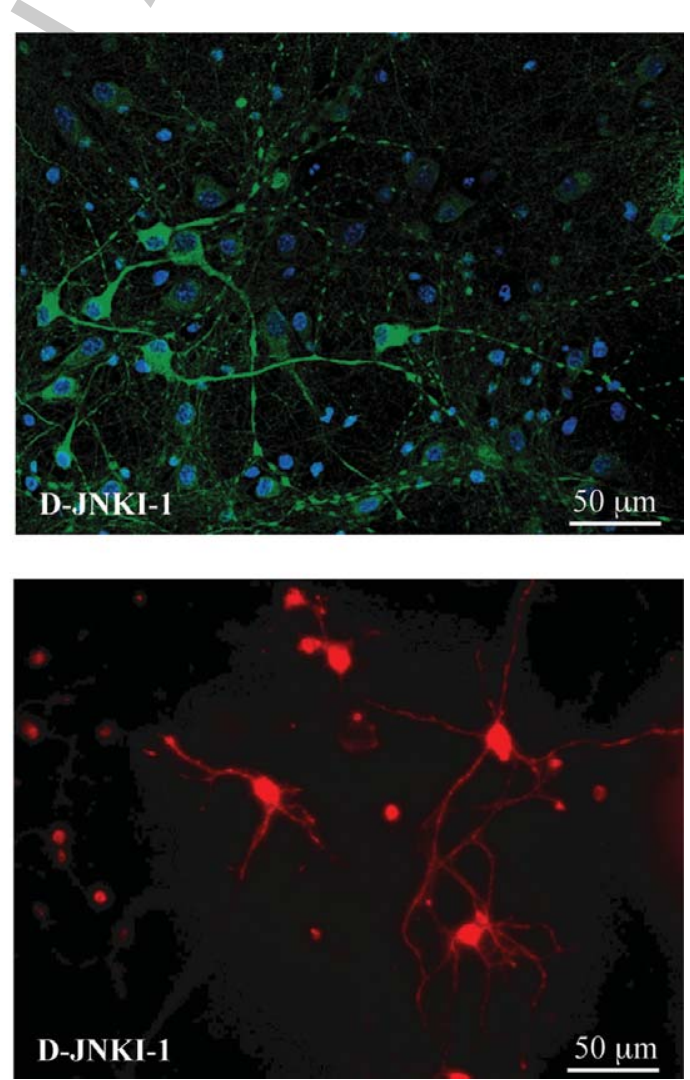

Fig. 3. D-JNKI-1 regulates $p$-tau AT8 distribution. Representative immunostaining images show that A) treatment with $4 \mu \mathrm{M}$ D-JNKI-1 for $24 \mathrm{~h}$ leads to a decrease in AT8 immunoreactivity (right panel: green $p$-tau AT8 - blue Hoechst, scale bar $50 \mu$ m). B) Neurons were stained for F-actin (phalloidin). Representative photomicrographs show that D-JNKI-1 does not affect the F-actin cytoskeleton and the neuronal architecture. All experiments were repeated at least six times (CTR $=$ control conditions). 
A

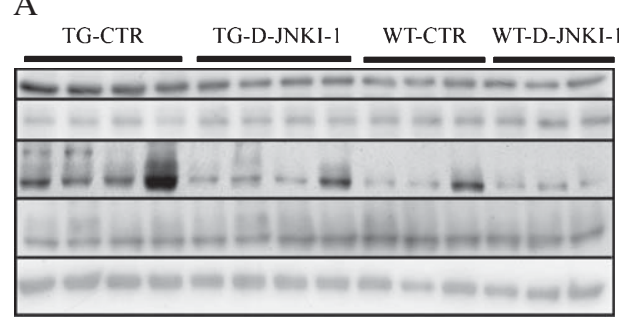

C

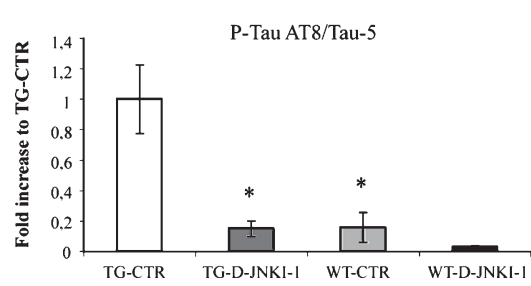

CEREBRAL CORTEX

B

P-c-Jun
c-Jun
P-Tau AT8
Tau-5
Actin

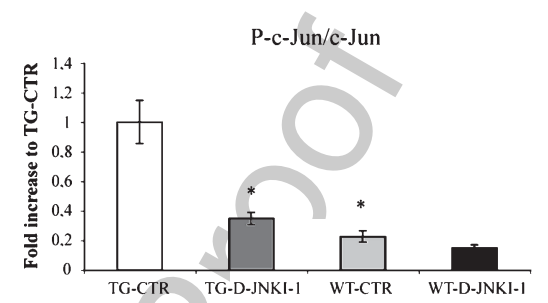

$\mathrm{D}$

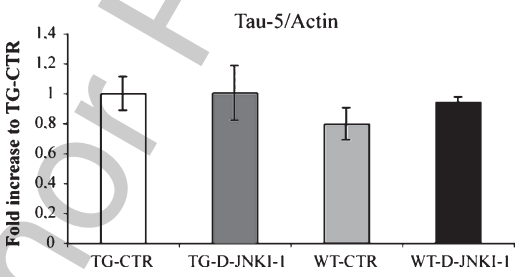

HIPPOCAMPUS

$\mathrm{E}$

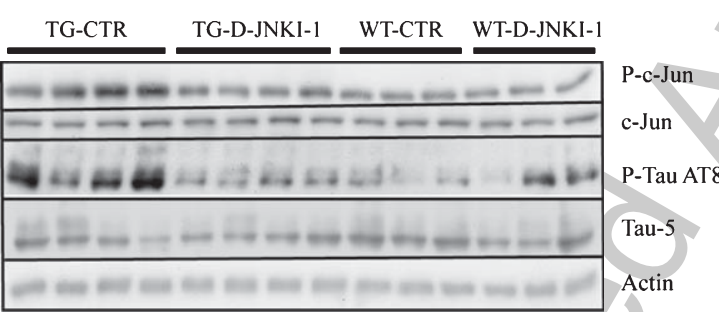

$\mathrm{F}$

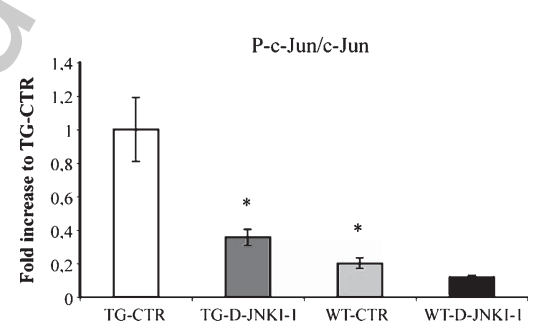

G

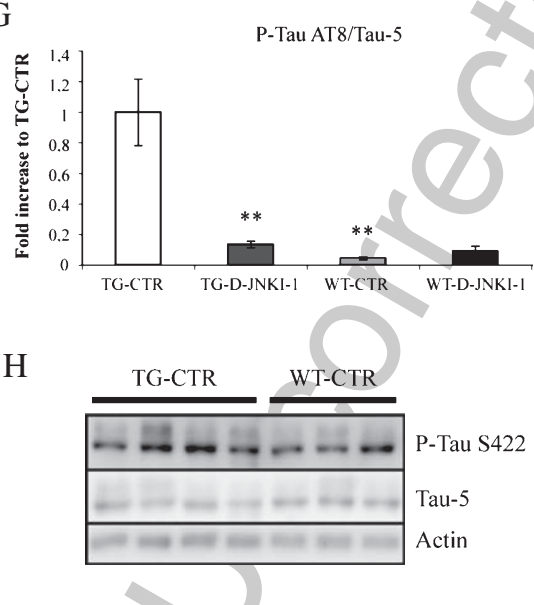

I

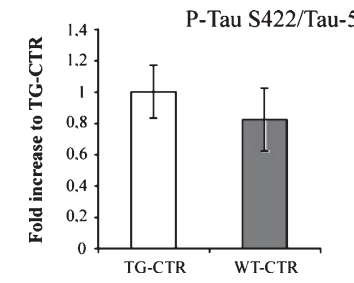

Fig. 4. D-JNKI-1 treatment inhibits p-c-Jun expression and reduces $p$-tau AT8 in the cortex and hippocampus of TgCRND8 mice. Cerebral Cortex: A) Representative Western blots of p-c-Jun, c-Jun, $p$-tau AT8, and Tau-5 from the cortex of TG-CTR, TG-D-JNKI-1, WT-CTR, and WT-D-JNKI-1 mice. B) In TG-CTR mice c-Jun activity is upregulated in comparison to WT-CTR. D-JNKI-1 reduced the p-c-Jun/c-Jun ratio by $60 \%$. C) In TG-CTR mice the $p$-tau AT8/Tau5 ratio is increased in comparison to WT-CTR mice. Chronic treatment with D-JNKI-1 reduces p-tau AT8/Tau5 ratio in TG mice to WT-CTR levels. D) Total levels of tau remain unchanged following treatment with D-JNKI-1 as shown by the Tau-5/Actin ratio (Two Way ANOVA - Tukey's Test $-* p<0.05)( \pm$ S.E.M.). Hippocampus: E) Representative Western blots of p-c-Jun, c-Jun, p-tau AT8, and Tau-5 of TG-CTR, TG-D-JNKI-1, WT-CTR, and WT-D-JNKI-1. F) In TG-CTR mice c-Jun activity is upregulated in comparison to WT-CTR. D-JNKI-1 reduces the p-c-Jun/c-Jun ratio by $60 \%$. G) $p$-tau/tau is significantly increased in Tg-CTR compared to WT-CTR mice. D-JNKI-1 chronic treatment leads to an $85 \%$ reduction of $p$-tau AT8/Tau-5 ratio. (Two Way ANOVA - Tukey's Test $-* p<0.05$, $* * p<0.01$ ) ( \pm S.E.M.). H) Representative Western blots of $p$-tau S422 in TG-CTR and WT-CTR mice. I) Densitometry analysis reveals no changes at $p$-tau S422 levels between TG-CTR and WT-CTR. Loading control: Actin. (Student's $t$-test) ( \pm S.E.M.). (TG-CTR=not treated TgCRND8 mice, TG-DJNKI-1 = D-JNKI-1 treated TgCRND8 mice, WT-CTR = not treated Wt mice, WT-DJ = D-JNKI-1 treated Wt mice). 
A FITC Brightfield

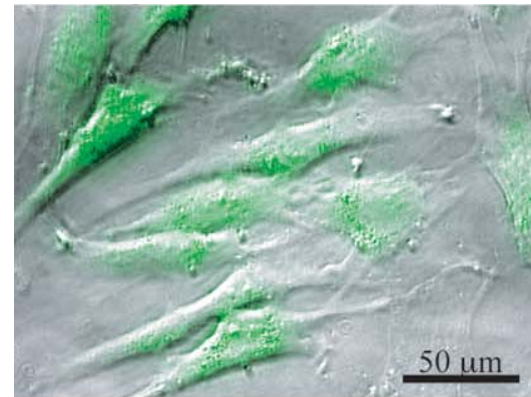

FITC

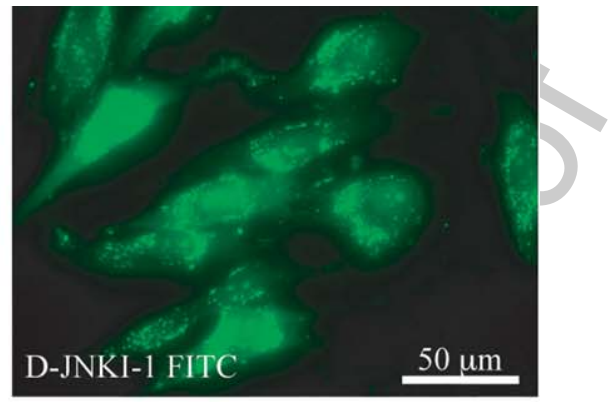

LDH D-JNKI1 24h

B

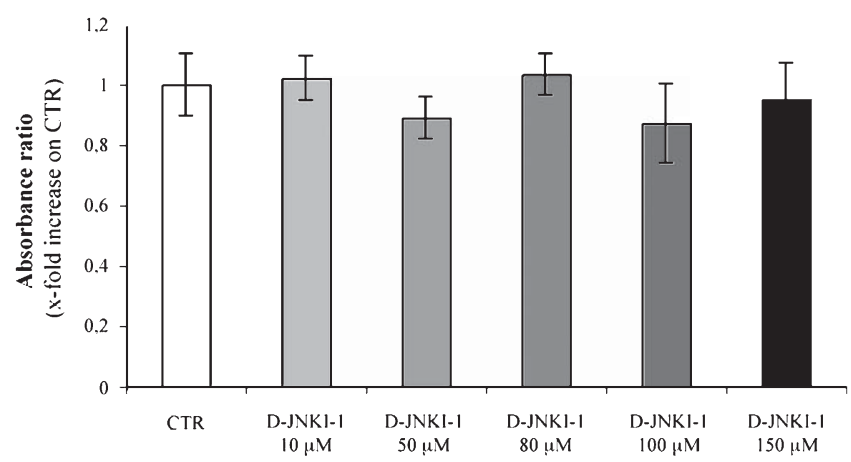

C

NA FIBROBLASTS
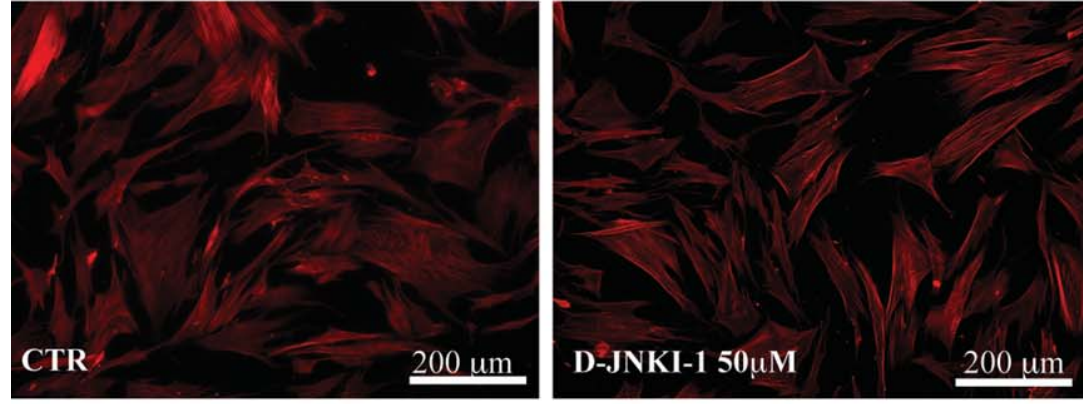

AD FIBROBLASTS
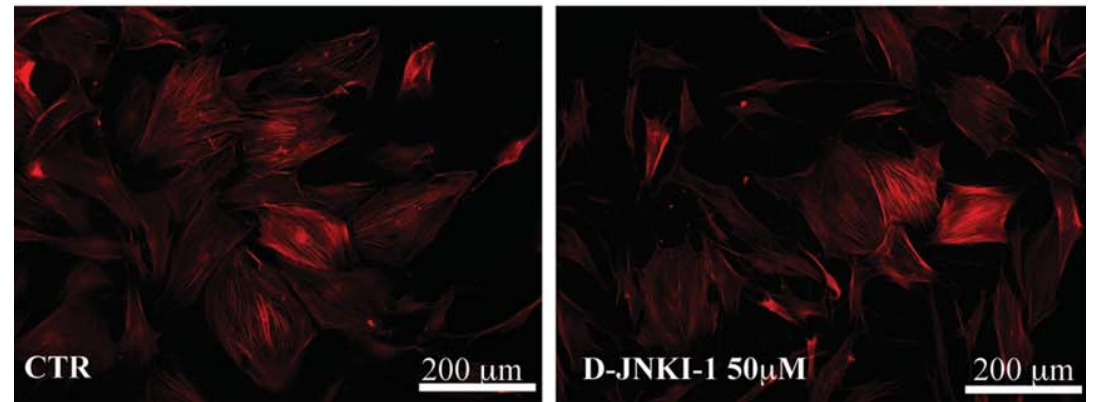

Fig. 5. Lack of toxicity and successful penetration by D-JNKI-1 in human fibroblasts. A) Exposure of fibroblasts to $50 \mu$ M FITC-labeled D-JNKI-1 for $24 \mathrm{~h}$ leads to accumulation of the peptide within the cell (left panel: Bright Field images with FITC-D-JNKI-1, right panel FITCD-JNKI-1 only, scale bar $50 \mu \mathrm{m}$ ). B) Incubation with D-JNKI-1 is not toxic as indicated by the absence of LDH leakage (One way ANOVA). C) Cells were stained for F-actin (phalloidin). Representative photomicrographs show that D-JNKI-1 does not affect the F-actin cytoskeleton of fibroblasts from healthy and/or AD subjects. (CTR = control conditions, $\mathrm{NA}=$ not affected subject, $\mathrm{AD}=\mathrm{AD}$ subject). 
Tukey's post-hoc test). We subsequently assessed the efficiency of D-JNKI-1 treatment in TgCRND8 mice by analyzing the effect of the peptide on the phosphorylation of c-Jun. D-JNKI-1 reduced the p-c-Jun/c-Jun ratio by $60 \%$ both in the cortex (Fig. 4A,B) and the hippocampus (Fig. 4E,F) ( $p<0.05$, two-way ANOVA, Tukey's post-hoc test).

Levels of $p$-tau (clone AT8) were examined by Western blotting in the cortex and in the hippocampus of Tg-D-JNKI-1 mice in comparison to untreated and to WT (treated and untreated) littermates. Total tau levels were detected by the anti-tau clone tau- 5 previously

A
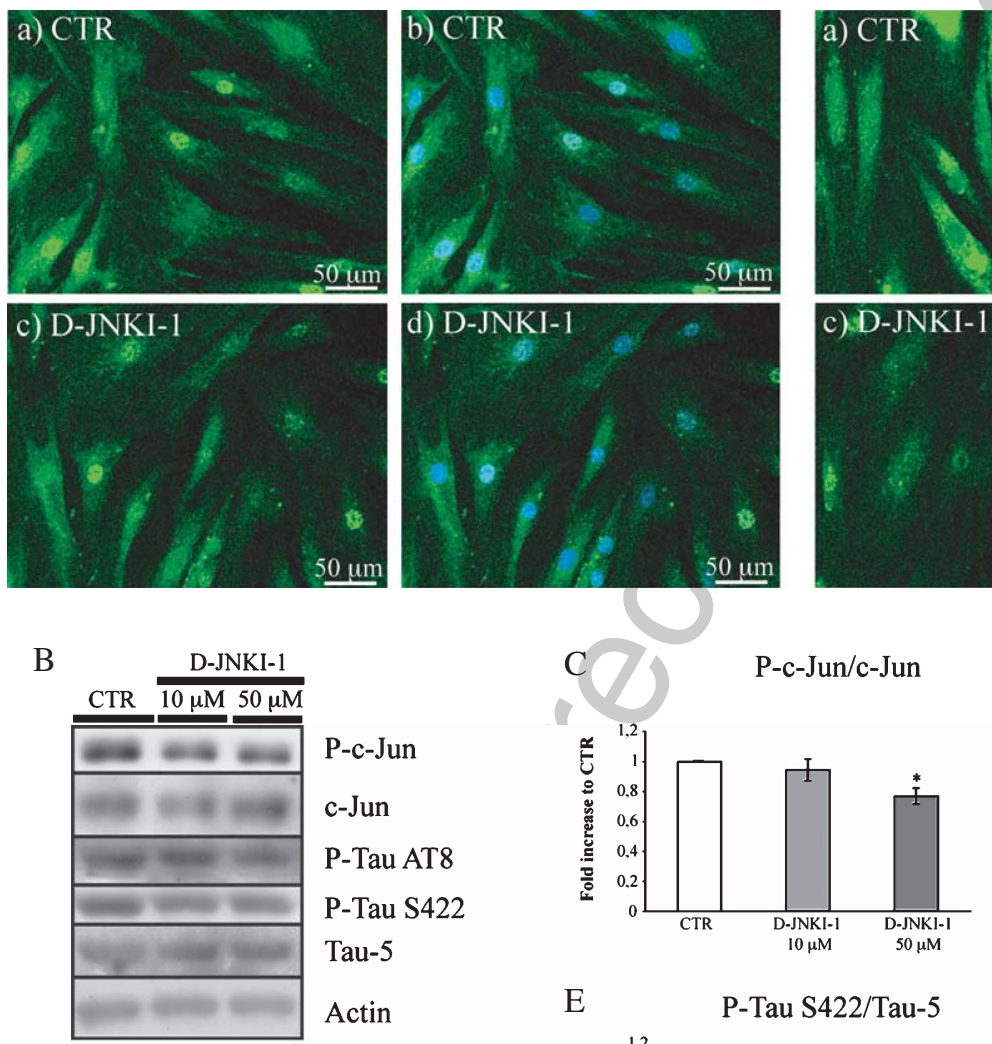

$\mathrm{E}$

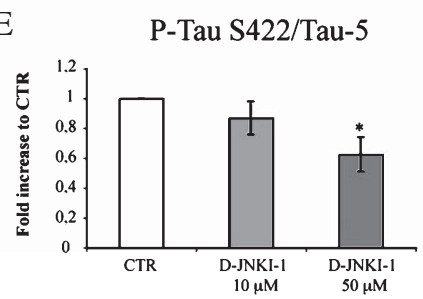

used in the same model by Bellucci et al. [16]. As opposed to the data we obtained in vitro, D-JNKI-1 had no effect on total tau expression as indicated by tau (clone tau-5)/Actin ratio in cortex (Fig. 4A-D).

As expected [16], $p$-tau (clone AT8)/tau (clone tau5) was significantly increased in the cortex of TG-CTR compared to WT-CTR mice $(85 \%, p<0.01$, two-way ANOVA, Tukey's post-hoc test) (Fig. 4A-C). Conversely, $p$-tau AT8 levels in TG-D-JNKI-1 mice were comparable to those detected in WT-CTR animals. More specifically, in cortex homogenates of TG-DJNKI-1 mice the $p$-tau AT8/tau (clone tau-5) ratio
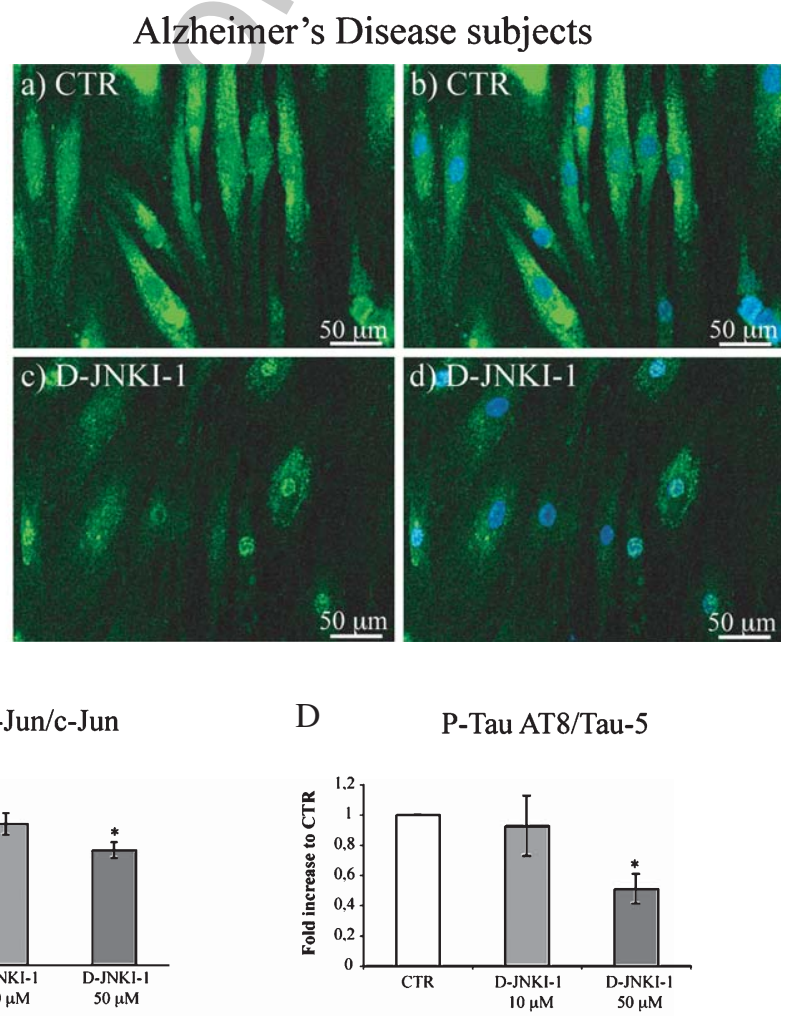

F

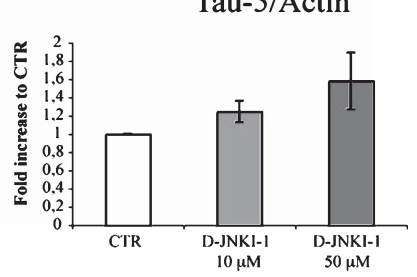

Fig. 6. D-JNKI-1 reduces tau phosphorylation in human fibroblasts. A) D-JNKI-1 reduces AT8 staining in fibroblasts from AD patients, but not in NA subjects (green $p$-tau AT8 - blue Hoechst, scale bar $50 \mu \mathrm{m})(\mathrm{CTR}=$ control conditions, NA = not affected subject, AD $=\mathrm{AD}$ subject). B) Representative Western blots of p-c-Jun, c-Jun, $p$-tau AT8, $p$-tau S422, and Tau-5 in human AD fibroblasts untreated (CTR) and treated with increasing concentrations of D-JNKI-1 (10-50 $\mu \mathrm{M})$ for $24 \mathrm{~h}$. C) Treatment with $50 \mu \mathrm{M}$ D-JNKI-1 reduces p-c-Jun/c-Jun ratio by $23 \%$. D) Treatment with $50 \mu \mathrm{M}$ D-JNKI-1 reduces $p$-tau AT8/Tau-5 ratio by $50 \%$, and E) D-JNKI-1 (50 $\mu \mathrm{M})$ also leads to a $38 \%$ reduction of $p$-tau S422/Tau-5 ratio. F) Total tau is not affected by treatment with D-JNKI-1. Loading control: Actin. (One Way ANOVA - Tukey's Test $-* p<0.05$ ) ( \pm S.E.M.). 
was significantly lower in comparison to TG-CTR mice $(-85 \%, p<0.05$, two-way ANOVA, Tukey's posthoc test) (Fig. 4A-C). Likewise, in the hippocampus the $p$-tau AT8/tau (clone tau-5) ratio was significantly increased in TG-CTR mice compared to WT-CTR mice $(95 \%, p<0.01$, two-way ANOVA, Tukey's posthoc test) and decreased in TG-D-JNKI-1 compared to untreated TG-CTR mice $(-85 \% p<0.05$, two-way ANOVA, Tukey's post-hoc test) (Fig. 4E-G).

We then examined the phosphorylation of the S422 tau site in Tg-CTR compared to WT-CTR mice. Since we could not observe changes in tau phosphorylation at $\mathrm{S} 422$ between Tg and Wt animals (Fig. 4H,I) we did not process D-JNKI-1 treated mice ( $p>0.05$, Student's $t$-test).

\section{Therapeutic efficacy of D-JNKI-1 was tested in} primary fibroblasts from AD patients

The effect of JNK inhibition on tau phosphorylation was tested in human fibroblasts from AD patients and in not affected subjects (NA). We first tested penetration and toxicity of D-JNKI-1 on these cells that are defined as a resistant cell line to cell permeable peptides (CPPs) [42].

Exposure to $50 \mu \mathrm{M}$ D-JNKI-1 resulted in $100 \%$ penetration after $24 \mathrm{~h}$ (Fig. 5A). Toxicity was assessed by measuring $\mathrm{LDH}$ release in the culture media: no signs of toxicity were detected even at doses as high as $150 \mu \mathrm{M}$ (Fig. 5B). Treatment of fibroblasts with D-JNKI-1 did not affect the cytoskeletal structure of fibroblasts, as demonstrated by phalloidin staining (Fig. 5C).

The inhibitory effect of D-JNKI-1 on the p-c-Jun/cJun ratio in this cellular model was tested by Western blotting. $50 \mu \mathrm{M}$ D-JNKI-1 reduced p-c-Jun/c-Jun ratio by $23 \%$ after $24 \mathrm{~h}(p<0.05$, One Way ANOVATukey's post-hoc test) ( \pm S.E.M.) (Fig. 6B,C).

We then evaluated the effect of D-JNKI-1 treatment on $p$-tau AT8 and tau expression and distribution. It is known that in cycling cells, like fibroblasts, tau is also localized in the nucleus and along mitotic chromosomes to regulate microtubules dynamic instability required for the rapid mitotic events [43]. Interestingly, $p$-tau AT8 distribution was quite different in NA healthy subjects and AD patients, suggesting a mislocation of the protein in pathological conditions. In NA fibroblasts $p$-tau AT8 staining was both nuclear and cytoplasmic [43], while in AD fibroblasts the phosphorylated protein was mainly cytoplasmic (Fig. 6A). D-JNKI-1 treatment reduced $p$-tau AT8 in fibroblasts from $\mathrm{AD}$ patients. On the other hand the strong reduc- tion of $p$-tau AT8, observed in AD patients, was less evident in D-JNKI-1 treated fibroblasts from NA subjects suggesting a major effect of D-JNKI-1 peptide on p-tau AT8 cytoplasmic pool (Fig. 6A).

To better investigate the effect of D-JNKI-1 on AD fibroblasts we quantified the $p$-tau/tau ratio by Western blotting. Treatment with D-JNKI-1, $50 \mu \mathrm{M}$, reduced the $p$-tau (clone AT8)/tau (clone tau-5) ratio by $50 \%$ (Fig. 6B-D) $(p<0.05$, One Way ANOVA- Tukey's Test) ( \pm S.E.M.). Moreover $p$-tau S422/tau (clone tau5 ) ratio was reduced by $38 \%$ (Fig. 6B-E) $(p<0.05$, One way ANOVA- Tukey's Test $)( \pm$ S.E.M. $)(p<0.05$ and $p<0.01$, One Way ANOVA- Tukey's Test) ( \pm S.E.M.). D-JNKI-1 did not affect tau (clone tau-5)/Actin ratio indicating that the peptide does not have any effects on total tau expression (Fig. 4B,F).

\section{DISCUSSION}

Neurofibrillary tangles composed of hyperphosphorylated tau are a major hallmark of AD. In the present study we investigated the phosphorylation of tau mediated by JNK at S202/T205 [44], recognized by the AT8 antibody, and S422 [26, 27]. As previously reported, phosphorylation at S202/T205 is an early event in tau hyperphosphorylation [45-47] and is associated with an early stage of the pathology in human AD brains and tauopathies [23, 25, 47]. Similarly, phosphorylation at S422 is seen in AD brains but not in normal brains [48]. However, this phosphorylation is not an early event in tau pathology since staining for $p$-tau S422 is rare in pretangle neurons [49]. Hyperphosphorylation of tau has been linked extensively to neurodegeneration [50, 51], and it involves a wide range of kinases. Some of the kinases responsible of tau phosphorylation, Cdk-5, GSK-3 $\beta$, and JNK [27, 52-57] are also responsible for A $\beta$ PP phosphorylation on T668 $[11,58-60]$, which is of crucial importance in $\beta$ cleavage and consequent production of $A \beta$ oligomers [61]. These kinases lie at the intersection between the two major histopathological hallmarks of $\mathrm{AD}$ a feature that renders them potential targets to inhibit the post-transcriptional modifications of two important AD proteins.

Among the kinases responsible of both tau and A $\beta P P$ phosphorylation JNK is particularly intriguing. Increased levels of JNK have been observed in AD brains while p-JNK co-localizes with $p$-tau in neurons of $\mathrm{AD}$ patients [4, 62]. Our aim was to investigate the role of JNK in tau phosphorylation. To the best of our knowledge almost all works reported have 
investigated tau phosphorylation using either in vitro models like cell free systems for kinase reactions, transiently transfected over-expressing cell systems [63, 64], or transgenic mouse models where kinases have been inducibly/conditionally expressed (e.g., [65, 66]). Due to the importance of tau phosphorylation in $\mathrm{AD}$ neurodegeneration further and more in depth studies are needed to better understand the mechanisms that regulate this process. For this purpose we used the most specific JNK inhibitor peptide D-JNKI-1 [30] and investigated the effect of JNK inhibition in both physiological conditions as well as in two AD models. The D-JNKI-1 peptide has been successfully used and inhibits phosphorylation of A $\beta P P$ in vitro $[13,14]$, as well as in vivo (Sclip et al., submitted manuscript). We demonstrated that, in all three models, JNK inhibition strongly reduces tau hyperphosphorylation at S202/T205.

The effect of the D-JNKI-1 inhibitor on tau hyperphosphorylation was initially tested in rat cortical neurons. Our findings demonstrate that in physiological conditions JNK is involved in tau phosphorylation both at S202/T205 and S422. Of note, D-JNKI-1 also exerted an effect on total tau protein as well as mRNA levels. Although this issue needs further investigation, it should be noted that this effect is restricted to control cortical neurons and it is absent in the two other models studied (TgCRND8 mice and human fibroblasts).

Subsequently we studied phosphorylation of tau by JNK in an in vivo AD mouse model (TgCRND8) following chronic treatment with D-JNKI-1. This model offers a powerful tool to study the early events occurring in $\mathrm{AD}$ pathology and to analyze the intracellular mechanisms of $\mathrm{AD}$ neurodegeneration in vivo. The TgCRND8 mice over-express the A $\beta P P$ with both Indiana and Swedish mutations and develop the AD phenotype very quickly [39]. In agreement with others $[16,39]$, we could show that TgCRND8 brains presented hyperphosphorylation of tau in the cortex and hippocampus at 7 months of age and after the formation of plaques (plaques at 3-5 months). Of note, chronic treatment with D-JNKI-1 completely reverted the pathological phosphorylation of tau (clone AT8) in the cortex and hippocampus of TgCRND8 mice, and importantly it did not interfere with the total levels of tau. Although one could argue that the effect of JNK inhibition on tau phosphorylation observed in TgCRND8 mice could result from altered A $\beta P P$ processing the results from the in vitro data would suggest that the effect is more direct. Further experiments, beyond the scope of this work would be required to confirm a direct interaction between JNK and tau.
Interestingly, we did not observe alterations of $p$-tau $\mathrm{S} 422$ levels in the TgCRND8 mice compared to $\mathrm{Wt}$ mice. Overall the results obtained on TgCRND8 brains demonstrated the importance of the JNK pathway in the early stage of tau hyperphosphorylation in vivo.

Finally we analyzed the effect of JNK inhibition in human AD fibroblasts, a model that is commonly used to elucidate the primary pathophysiological mechanisms leading to $\mathrm{AD}$ and to avoid the variability that often derives from post-mortem studies. Treatment with D-JNKI-1 $(50 \mu \mathrm{M})$ led to a clear reduction of the $p$-tau (clone AT8)/tau (Clone tau-5) and $p$-tau S422/tau (Clone tau-5) ratio in all AD human fibroblasts. Notably, we could show that D-JNKI-1 reduced cytoplasmic AT8 staining in AD subjects but not in healthy control (not affected) fibroblasts. Such findings are indicative of a differential role of JNK in pathological and control conditions suggesting the involvement of a different array of kinases acting on tau protein or alternatively, a differential spatial distribution of $p$-tau pool in the molecular cascade leading to AD. Whether those differences are confined to the peripheral tissue is worth further investigation. Nevertheless our data demonstrate the similarity between human fibroblasts and mouse AD pathology and support the use of this peripheral tissue for the study of AD.

Altogether our findings underline the important contribution of JNK on tau physiological but most importantly pathological phosphorylation. The reduction of tau phosphorylation has been proposed as a therapeutic approach for AD [67]. Treatment with DJNKI-1 clearly demonstrates the importance of the JNK pathway on tau pathological phosphorylation and indicates JNK as an innovative therapeutic target in AD and other neurodegenerative disorders.

\section{ACKNOWLEDGMENTS}

This study was supported by the Marie Curie Industry-Academia Partnerships and Pathways (IAPP) cPADS; San Paolo 2008-2437; CARIPLO 2009-2425. Ricerca Corrente, Italian Ministry of Health; Fondazione CARIPLO 2009-2633. There are no actual or potential conflicts of interest. We thank Dr. Feligioni for his scientific advice.

Written informed consent was obtained from all subjects or, where appropriate, their caregivers, following the procedures approved by the hospital local ethical committee. All experimental procedures on animals were performed in accordance with the European Communities Council Directive of 24 November 1986 
(86/609/EEC) and all efforts were made to minimize animal suffering.

Authors' disclosures available online (http://www.jalz.com/disclosures/view.php?id=846).

\section{REFERENCES}

[1] Weston CR, Davis RJ (2007) The JNK signal transduction pathway. Curr Opin Cell Biol 19, 142-149.

[2] Borsello T, Forloni G (2007) JNK signalling: a possible target to prevent neurodegeneration. Curr Pharm Des 13, 18751886.

[3] Zhu X, Castellani RJ, Takeda A, Nunomura A, Atwood CS, Perry G, Smith MA (2001) Differential activation of neuronal ERK, JNK/SAPK and p38 in Alzheimer disease: the 'two hit' hypothesis. Mech Ageing Dev 123, 39-46.

[4] Zhu X, Raina AK, Rottkamp CA, Aliev G, Perry G, Boux H, Smith MA (2001) Activation and redistribution of c-jun Nterminal kinase/stress activated protein kinase in degenerating neurons in Alzheimer's disease. J Neurochem 76, 435-441.

[5] Shoji M, Iwakami N, Takeuchi S, Waragai M, Suzuki M, Kanazawa I, Lippa CF, Ono S, Okazawa H (2000) JNK activation is associated with intracellular beta-amyloid accumulation. Brain Res Mol Brain Res 85, 221-233.

[6] Sato S, Tatebayashi Y, Akagi T, Chui DH, Murayama M, Miyasaka T, Planel E, Tanemura K, Sun X, Hashikawa T, Yoshioka K, Ishiguro K, Takashima A (2002) Aberrant tau phosphorylation by glycogen synthase kinase- 3 beta and JNK3 induces oligomeric tau fibrils in COS-7 cells. $J$ Biol Chem 277, 42060-42065.

[7] Thakur A, Wang X, Siedlak SL, Perry G, Smith MA, Zhu X (2007) c-Jun phosphorylation in Alzheimer disease. J Neurosci Res 85, 1668-1673.

[8] Zhu X, Ogawa O, Wang Y, Perry G, Smith MA (2003) $\mathrm{JKK} 1$, an upstream activator of JNK/SAPK, is activated in Alzheimer's disease. J Neurochem 85, 87-93.

[9] Morishima Y, Gotoh Y, Zieg J, Barrett T, Takano H, Flavell R, Davis RJ, Shirasaki Y, Greenberg ME (2001) Beta-amyloid induces neuronal apoptosis via a mechanism that involves the c-Jun N-terminal kinase pathway and the induction of Fas ligand. J Neurosci 21, 7551-7560.

[10] Minogue AM, Schmid AW, Fogarty MP, Moore AC, Campbell VA, Herron CE, Lynch MA (2003) Activation of the c-Jun $\mathrm{N}$-terminal kinase signaling cascade mediates the effect of amyloid-beta on long term potentiation and cell death in hippocampus: a role for interleukin-1 beta? J Biol Chem 278, 27971-27980.

[11] Muresan Z, Muresan V (2005) c-Jun $\mathrm{NH}_{2}$-terminal kinaseinteracting protein-3 facilitates phosphorylation and controls localization of amyloid-beta precursor protein. J Neurosci $\mathbf{2 5}$, 3741-3751.

[12] Vingtdeux V, Hamdane M, Gompel M, Begard S, Drobecq H, Ghestem A, Grosjean ME, Kostanjevecki V, Grognet P, Vanmechelen E, Buee L, Delacourte A, Sergeant N (2005) Phosphorylation of amyloid precursor carboxy-terminal fragments enhances their processing by a gamma-secretasedependent mechanism. Neurobiol Dis 20, 625-637.

[13] Colombo A, Repici M, Pesaresi M, Santambrogio S, Forloni G, Borsello T (2007) The TAT-JNK inhibitor peptide interferes with beta amyloid protein stability. Cell Death Differ 14, 1845-1848.

[14] Colombo A, Bastone A, Ploia C, Sclip A, Salmona M, Forloni G, Borsello T (2009) JNK regulates APP cleavage and degradation in a model of Alzheimer's disease. Neurobiol Dis 33, 518-525.

[15] Ferrer I, Blanco R, Carmona M, Puig B (2001) Phosphorylated mitogen-activated protein kinase (MAPK/ERK-P), protein kinase of $38 \mathrm{kDa}$ (p38-P), stress-activated protein kinase (SAPK/JNK-P), and calcium/calmodulin-dependent kinase II (CaM kinase II) are differentially expressed in tau deposits in neurons and glial cells in tauopathies. J Neural Transm 108, 1397-1415.

[16] Bellucci A, Rosi MC, Grossi C, Fiorentini A, Luccarini I, Casamenti F (2007) Abnormal processing of tau in the brain of aged TgCRND8 mice. Neurobiol Dis 27, 328-338.

[17] Ma QL, Yang F, Rosario ER, Ubeda OJ, Beech W, Gant DJ, Chen PP, Hudspeth B, Chen C, Zhao Y, Vinters HV, Frautschy SA, Cole GM (2009) Beta-amyloid oligomers induce phosphorylation of tau and inactivation of insulin receptor substrate via c-Jun N-terminal kinase signaling: suppression by omega- 3 fatty acids and curcumin. J Neurosci $\mathbf{2 9}$, 9078-9089.

[18] Vogel J, Anand VS, Ludwig B, Nawoschik S, Dunlop J, Braithwaite SP (2009) The JNK pathway amplifies and drives subcellular changes in tau phosphorylation. Neuropharmacology $\mathbf{5 7}, 539-550$

[19] Hardy J, Selkoe DJ (2002) The amyloid hypothesis of Alzheimer's disease: progress and problems on the road to therapeutics. Science 297, 353-356.

[20] Lahiri DK, Farlow MR, Sambamurti K, Greig NH, Giacobini E, Schneider LS (2003) A critical analysis of new molecular targets and strategies for drug developments in Alzheimer's disease. Curr Drug Targets 4, 97-112.

[21] Noble W, Planel E, Zehr C, Olm V, Meyerson J, Suleman F, Gaynor K, Wang L, LaFrancois J, Feinstein B, Burns M, Krishnamurthy P, Wen Y, Bhat R, Lewis J, Dickson D, Duff $\mathrm{K}$ (2005) Inhibition of glycogen synthase kinase-3 by lithium correlates with reduced tauopathy and degeneration in vivo. Proc Natl Acad Sci U S A 102, 6990-6995.

[22] Sereno L, Coma M, Rodriguez M, Sanchez-Ferrer P, Sanchez MB, Gich I, Agullo JM, Perez M, Avila J, Guardia-Laguarta C, Clarimon J, Lleo A, Gomez-Isla T (2009) A novel GSK3 beta inhibitor reduces Alzheimer's pathology and rescues neuronal loss in vivo. Neurobiol Dis 35, 359-367.

[23] Su JH, Cummings BJ, Cotman CW (1994) Early phosphorylation of tau in Alzheimer's disease occurs at Ser-202 and is preferentially located within neurites. Neuroreport $\mathbf{5}, 2358$ 2362.

[24] Augustinack JC, Schneider A, Mandelkow EM, Hyman BT (2002) Specific tau phosphorylation sites correlate with severity of neuronal cytopathology in Alzheimer's disease. Acta Neuropathol 103, 26-35.

[25] Luna-Munoz J, Chavez-Macias L, Garcia-Sierra F, Mena R (2007) Earliest stages of tau conformational changes are related to the appearance of a sequence of specific phosphodependent tau epitopes in Alzheimer's disease. J Alzheimers Dis 12, 365-375.

[26] Yoshida H, Hastie CJ, McLauchlan H, Cohen P, Goedert M (2004) Phosphorylation of microtubule-associated protein tau by isoforms of c-Jun N-terminal kinase (JNK). J Neurochem 90, 352-358

[27] Reynolds CH, Utton MA, Gibb GM, Yates A, Anderton BH (1997) Stress-activated protein kinase/c-jun N-terminal kinase phosphorylates tau protein. J Neurochem 68, 17361744.

[28] Grueninger F, Bohrmann B, Czech C, Ballard TM, Frey JR, Weidensteiner C, von Kienlin M, Ozmen L, Phosphorylation of Tau at S422 is enhanced by Abeta in TauPS2APP triple transgenic mice. Neurobiol Dis 37, 294-306. 
[29] Malaplate-Armand C, Desbene C, Pillot T, Olivier JL (2009) [Biomarkers for early diagnosis of Alzheimer's disease: current update and future directions]. Rev Neurol (Paris) 165, 511-520.

[30] Borsello T, Clarke PG, Hirt L, Vercelli A, Repici M, Schorderet DF, Bogousslavsky J, Bonny C (2003) A peptide inhibitor of c-Jun N-terminal kinase protects against excitotoxicity and cerebral ischemia. Nat Med 9, 1180-1186.

[31] Bonny C, Oberson A, Negri S, Sauser C, Schorderet DF (2001) Cell-permeable peptide inhibitors of JNK: novel blockers of beta-cell death. Diabetes 50, 77-82.

[32] Repici M, Mare L, Colombo A, Ploia C, Sclip A, Bonny C, Nicod P, Salmona M, Borsello T (2009) c-Jun Nterminal kinase binding domain-dependent phosphorylation of mitogen-activated protein kinase kinase 4 and mitogenactivated protein kinase kinase 7 and balancing cross-talk between c-Jun $\mathrm{N}$-terminal kinase and extracellular signalregulated kinase pathways in cortical neurons. Neuroscience 159, 94-103.

[33] Antoniou X, Sclip A, Ploia C, Colombo A, Moroy G, Borsello $\mathrm{T}$, JNK contributes to Hif-1 alpha regulation in hypoxic neurons. Molecules 15, 114-127.

[34] Lesuisse C, Martin LJ (2002) Immature and mature cortical neurons engage different apoptotic mechanisms involving caspase-3 and the mitogen-activated protein kinase pathway. $J$ Cereb Blood Flow Metab 22, 935-950.

[35] Li JH, Wang YH, Wolfe BB, Krueger KE, Corsi L, Stocca G, Vicini S (1998) Developmental changes in localization of NMDA receptor subunits in primary cultures of cortical neurons. Eur J Neurosci 10, 1704-1715.

[36] Benussi L, Govoni S, Gasparini L, Binetti G, Trabucchi M, Bianchetti A, Racchi M (1998) Specific role for protein kinase $\mathrm{C}$ alpha in the constitutive and regulated secretion of amyloid precursor protein in human skin fibroblasts. Neurosci Lett 240, $97-101$.

[37] Vandesompele J, De Preter K, Pattyn F, Poppe B, Van Roy N, De Paepe A, Speleman F (2002) Accurate normalization of real-time quantitative RT-PCR data by geometric averaging of multiple internal control genes. Genome Biol 3, RESEARCH0034.

[38] Zhao R, Zhang S, Xu Z, Ju L, Lu D, Yao G (2007) Studying gene expression profile of rat neuron exposed to $1800 \mathrm{MHz}$ radiofrequency electromagnetic fields with cDNA microassay. Toxicology 235, 167-175.

[39] Chishti MA, Yang DS, Janus C, Phinney AL, Horne P, Pearson J, Strome R, Zuker N, Loukides J, French J, Turner S, Lozza G, Grilli M, Kunicki S, Morissette C, Paquette J, Gervais F, Bergeron C, Fraser PE, Carlson GA, George-Hyslop PS, Westaway D (2001) Early-onset amyloid deposition and cognitive deficits in transgenic mice expressing a double mutant form of amyloid precursor protein 695. J Biol Chem 276, 21562-21570.

[40] Repici M, Centeno C, Tomasi S, Forloni G, Bonny C, Vercelli A, Borsello T (2007) Time-course of c-Jun N-terminal kinase activation after cerebral ischemia and effect of D-JNKI1 on c-Jun and caspase-3 activation. Neuroscience 150, 40-49.

[41] Bellucci A, Luccarini I, Scali C, Prosperi C, Giovannini MG, Pepeu G, Casamenti F (2006) Cholinergic dysfunction, neuronal damage and axonal loss in TgCRND8 mice. Neurobiol Dis 23, 260-272.

[42] Cardozo AK, Buchillier V, Mathieu M, Chen J, Ortis F, Ladriere L, Allaman-Pillet N, Poirot O, Kellenberger S, Beckmann JS, Eizirik DL, Bonny C, Maurer F (2007) Cell-permeable peptides induce dose- and length-dependent cytotoxic effects. Biochim Biophys Acta 1768, 2222-2234.
[43] Rossi G, Dalpra L, Crosti F, Lissoni S, Sciacca FL, Catania M, Di Fede G, Mangieri M, Giaccone G, Croci D, Tagliavini F (2008) A new function of microtubule-associated protein tau: involvement in chromosome stability. Cell Cycle 7, 17881794.

[44] Goedert M, Jakes R, Vanmechelen E (1995) Monoclonal antibody AT8 recognises tau protein phosphorylated at both serine 202 and threonine 205. Neurosci Lett 189, 167-169.

[45] Kimura T, Ono T, Takamatsu J, Yamamoto H, Ikegami K, Kondo A, Hasegawa M, Ihara Y, Miyamoto E, Miyakawa T (1996) Sequential changes of tau-site-specific phosphorylation during development of paired helical filaments. Dementia 7, 177-181.

[46] Lauckner J, Frey P, Geula C (2003) Comparative distribution of tau phosphorylated at Ser262 in pre-tangles and tangles. Neurobiol Aging 24, 767-776.

[47] Maurage CA, Sergeant N, Ruchoux MM, Hauw JJ, Delacourte A (2003) Phosphorylated serine 199 of microtubuleassociated protein tau is a neuronal epitope abundantly expressed in youth and an early marker of tau pathology. Acta Neuropathol 105, 89-97.

[48] Bussiere T, Hof PR, Mailliot C, Brown CD, Caillet-Boudin ML, Perl DP, Buee L, Delacourte A (1999) Phosphorylated serine 422 on tau proteins is a pathological epitope found in several diseases with neurofibrillary degeneration. Acta Neuropathol $97,221-230$.

[49] Johnson GV, Stoothoff WH (2004) Tau phosphorylation in neuronal cell function and dysfunction. J Cell Sci 117, 57215729

[50] Ashe KH (2007) A tale about tau. N Engl J Med 357, 933-935

[51] Lee VM, Trojanowski JQ (2001) Transgenic mouse models of tauopathies: prospects for animal models of Pick's disease. Neurology 56, S26-S30.

[52] Buee-Scherrer V, Goedert M (2002) Phosphorylation of microtubule-associated protein tau by stress-activated protein kinases in intact cells. FEBS Lett 515, 151-154.

[53] Gallo JM, Hanger DP, Twist EC, Kosik KS, Anderton BH (1992) Expression and phosphorylation of a three-repeat isoform of tau in transfected non-neuronal cells. Biochem J 286 (Pt 2), 399-404.

[54] Mandelkow EM, Drewes G, Biernat J, Gustke N, Van Lint J, Vandenheede JR, Mandelkow E (1992) Glycogen synthase kinase-3 and the Alzheimer-like state of microtubule-associated protein tau. FEBS Lett 314, 315-321.

[55] Kobayashi S, Ishiguro K, Omori A, Takamatsu M, Arioka M, Imahori K, Uchida T (1993) A cdc2-related kinase PSSALRE/cdk5 is homologous with the $30 \mathrm{kDa}$ subunit of tau protein kinase II, a proline-directed protein kinase associated with microtubule. FEBS Lett 335, 171-175.

[56] Paudel HK, Lew J, Ali Z, Wang JH (1993) Brain proline-directed protein kinase phosphorylates tau on sites that are abnormally phosphorylated in tau associated with Alzheimer's paired helical filaments. J Biol Chem 268, 23512-23518.

[57] Reynolds CH, Nebreda AR, Gibb GM, Utton MA, Anderton BH (1997) Reactivating kinase/p38 phosphorylates tau protein in vitro. J Neurochem 69, 191-198.

[58] Aplin AE, Gibb GM, Jacobsen JS, Gallo JM, Anderton BH (1996) In vitro phosphorylation of the cytoplasmic domain of the amyloid precursor protein by glycogen synthase kinase3 beta. J Neurochem 67, 699-707.

[59] Iijima K, Ando K, Takeda S, Satoh Y, Seki T, Itohara S, Greengard P, Kirino Y, Nairn AC, Suzuki T (2000) Neuronspecific phosphorylation of Alzheimer's beta-amyloid precursor protein by cyclin-dependent kinase 5 . J Neurochem $\mathbf{7 5}$, 1085-1091. 
[60] Standen CL, Brownlees J, Grierson AJ, Kesavapany S, Lau KF, McLoughlin DM, Miller CC (2001) Phosphorylation of thr(668) in the cytoplasmic domain of the Alzheimer's disease amyloid precursor protein by stress-activated protein kinase 1 b (Jun N-terminal kinase-3). J Neurochem 76, 316-320.

[61] Lee MS, Kao SC, Lemere CA, Xia W, Tseng HC, Zhou Y, Neve R, Ahlijanian MK, Tsai LH (2003) APP processing is regulated by cytoplasmic phosphorylation. J Cell Biol 163, 83-95.

[62] Mohit AA, Martin JH, Miller CA (1995) p493F12 kinase: a novel MAP kinase expressed in a subset of neurons in the human nervous system. Neuron 14, 67-78.

[63] Zheng-Fischhofer Q, Biernat J, Mandelkow EM, Illenberger S, Godemann R, Mandelkow E (1998) Sequential phosphorylation of Tau by glycogen synthase kinase-3 beta and protein kinase A at Thr212 and Ser214 generates the Alzheimer-specific epitope of antibody AT100 and requires a paired-helical-filament-like conformation. Eur J Biochem 252, 542-552.

[64] Shea TB, Cressman CM (1999) The order of exposure of tau to signal transduction kinases alters the generation of "AD-like" phosphoepitopes. Cell Mol Neurobiol 19, 223-233.

[65] Cruz JC, Tseng HC, Goldman JA, Shih H, Tsai LH (2003) Aberrant Cdk5 activation by $\mathrm{p} 25$ triggers pathological events leading to neurodegeneration and neurofibrillary tangles. Neuron 40, 471-483.

[66] Lucas JJ, Hernandez F, Gomez-Ramos P, Moran MA, Hen R, Avila J (2001) Decreased nuclear beta-catenin, tau hyperphosphorylation and neurodegeneration in GSK-3 beta conditional transgenic mice. Embo J 20, 27-39.

[67] Hanger DP, Anderton BH, Noble W (2009) Tau phosphorylation: the therapeutic challenge for neurodegenerative disease. Trends Mol Med 15, 112-119.
873 